\section{White Swallows}

Mr. Herbert W. Page, in Nature, vol. xviji. p. 540, refers to the rare occurrence of a white Hirundo riparia.

I may mention that two white swallows of that species were captured in a high bank of sand at Hungryside, on the Forth and Clyde Canal, by $\mathrm{Mr}$. Martin, of that place, in August, 1876 , which I exhibited at a meeting of the Natural History Society of Glasgow, August 26, 1878. Both birds were white all over, with the exception of a brown tinge on the back of one of them. Mr. Stevenson, in his "Birds of Norfolk," vol. i. p. 342, mentions a light cream-coloured variety got at Eaton in July, 186r, and another at Weasenham in the following September.

Glasgow, September 27

\section{Secondary Lunar Rainbow}

DURING the very stormy and unsettled weather we had about a fortnight ago, I was one of a party of friends on a visit at a country-house near Huntly, about forty miles from this, who were witnesses, on the evening of Sunday, ${ }_{5}{ }^{\text {th }}$ inst., to a very striking, and, as a friend well versed in meteorology has since informed me, very uncommon phenomenon. It was that not only of a complete and brilliant primary lunar rainbow with colours, but also, a few minutes later, of a complete and welldefined, but, of course, less brilliant, secondary bow. No trace of colour could be observed on the secondary, but, inside the primary, the space seemed, in contrast with the faint moonlight, even more brilliantly and uniformly illuminated than $I$ recollect ever to have seen it within a solar rainbow. The time was about eleven o'clock, and the centre of the bows, therefore, bore about W. or a little to the $N$. of W.

R. WALKER

Aberdeen, September 30

\section{BONE CAVES IN STYRIA}

I. TWO prehistoric implements, found some years ago in the "Badel" Cave, near Peggau, in Styria, are preserved in the Museum of the Johanneum, at Gratz. Count G. Wurmbrand has lately conducted an exploration of this cave. The floor is formed for the most part of a layer of fragmentary stalagmite, about seven centimetres thick, resting on a loam, with bones and gravel, forty-three to seventy centimetres thick. A peculiar laminated and very compact loam, permeated by a blackish substance (pyrolusite) lies on the rocky bottom. In the loam have been found abundant bones and teeth of Ursus spelcus, undeterminable remains of rodents, a canine of a stag, bones gnawed by hycenx, \&c., but no human remains or relics.

2. In a cave on the north slope of the Erzberg, east of Wildalpe, in Upper Styria, Dr. A. Redtenbacher has found abundance of bones and teeth of Ursus spelazs. All these bones, except the phalanges, were broken; and the long ones of the extremities were split longitudinally.

3. On July I of this year, Dr. R. Hoernes and Dr. R. von Fleischhaker visited the Drachenhöhle (cave of Dragons) near Mixniz, about 1,292 (Austrian) feet above the town, and extending I, 440 feet into the rock, with an entrance 90 feet high and 72 feet wide. The floor of the cave is mostly covered with reddish-yellow cave-loam; but rock-fragments abound within the entrance. The superficial loam had been searched long ago. The inner parts of the cave, accessible only by ladders, were nearly untouched. On the day mentioned, numerous remains of Ursus spelaus, both young and adult, fragments of jaws with teeth, single teeth, long bones, ribs, phalanges, \&c., were soon found. Some of the teeth and bones in the terminal fissure of the cave could have been brought there only by moving water. No other animal but the cavebear was represented by the remains met with.

In the portion of the cave next the entrance, a still untouched layer of fragmentary stalagmite, including angular pieces of rock (some very large) was found

I Imperial:Geological Institute of Vienna Report, Juiy $3 x, 1878$. beneath an accumulation of rock-fragments. Underneath it is an irregular dark-brown and nearly black stratum, about 15 centimetres thick, containing charcoal and partially burnt bones; and in a brown loam, immediately beneath, similar objects were abundant. These bones, differing from those of the yellowish loam of the inner cave, by their greater consistence and dark colour, belong mostly to Ursus spelceus, and a few to an undetermined ungulate. The long bones are nearly all broken. Among these dark-coloured bones are phalanges, cervical vertebræ, and the lower portion of a right humerus measuring 16 centimetres between the condyles, which must have belonged to a colossal individual. The connection of the cervical vertebra (the atlas bearing traces of fire), and the presence of several other bones of this individual (as well as those of smaller ones) lead to the conclusion that it was brought into the cave after being killed, and prepared there for the food of the cave-folk. Noimplements were found.

\section{OUR ASTRONOMICAL COLUMN}

THE SATELLITES OF MARS.-The results of the complete reduction and discussion of the Washington observations of the satellites of Mars, undertaken by their discoverer, Prof. Asaph Hall, have just been published by the United States Naval Observatory. The observations of the outer satellite Deimos extend from I877, August II, to October 3I, and those of the inner one, Phobos, from August 17 to October 15. On November 7 and 12 the satellites were looked for, but could not be seen. In treating these observations with the view to the determination of the most probable orbital elements of the satellites, Prof. Hall assumes in the first place that their paths are circular, and by a graphical projection finds the angle between the orbit-plane and the plane perpendicular to the line of sight, as well as the angle of position of the major axis of the ellipse into which the circular path is projected. The resulting elements are then compared with the observations, and elliptical elements deduced from the resulting differences between calculation and observation, both for position and distance, by means of equations of condition. Thus the following values of the elliptical elements have been obtained from the Washington observations alone :-

Deimos. Pновоs.

Epoch 1877 , August 28.0 Greenwich Mean Time. h. m. s. h. m.

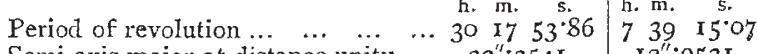
Semi-axis major at distance unity ... $32^{\prime \prime} 354 \mathrm{r} \quad \mathrm{r}^{\prime \prime} \cdot 953 \mathrm{I}$

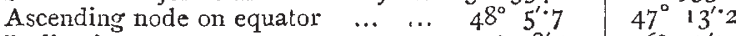

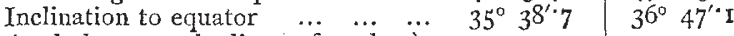
Angle between the lines of nodes $\dddot{3} \begin{array}{lll}40^{\circ} 53^{\prime} \cdot 6 & 45^{\circ} 30^{\prime} \cdot 4\end{array}$ $\left.\begin{array}{lllll}\text { and apsides } & \ldots & \ldots & \ldots & \ldots\end{array}\right\}$\begin{tabular}{cc|cc}
$40^{\circ}$ & $53^{\circ} 6$ & $45^{\circ}$ & $30^{\circ}$ \\
\hline
\end{tabular} \begin{tabular}{lcccccc|cc} 
Distance from node at epocb & $\ldots$ & $\ldots$ & $357^{\circ}$ & $30^{\prime} \cdot 5$ & $285^{\circ}$ & $20^{\prime} \cdot 2$ \\
Eccentricity & $\ldots$ & $\ldots$ & $\ldots$ & $\ldots$ & $\ldots$ & $0^{\circ} 00574 \mathrm{I}$ & $0^{\circ} 032079$
\end{tabular}

It will be seen that the planes of the orbits of the satellites are nearly coincident with the equator of Mars, the ascending node of which for the above epoch is in $47^{\circ} 56^{\prime}$, and the inclination $39^{\circ} 45^{\prime}$. Prof. Hall considers the elements to be determined with tolerable accuracy, with the exception of the periodic times, which remain to be decided within closer limits from the observations of another opposition; nevertheless they are sufficiently exact to carry forward an ephemeris to 1879 . The eccentricity in the case of Deimos is so small that for most purposes of calculation circular elements will suffice. In the case of Phobos, Prof. Hall thinks the eccentricity has a real existence, every comparison of distance with the circular orbit confirming it.

The mass of the planet deduced from the measures of Deimos is $\frac{1}{309513}$, and from those of Phobos $\frac{1}{3078+56}$, that of the sun being taken as unity; the adopted mean value 